\title{
'Roots of Empathy': A research study on its impact on teachers in Western Australia.
}

\author{
Glenda Cain \\ Dr Yvonne Carnellor \\ Curtin University of Technology, Western Australia
}

\begin{abstract}
If the view espoused in the literature is that social emotional competence is essential for academic learning and achievement, what does this mean for the classroom teacher? (McCombs, 2004). What is emotional literacy? How can emotional competency be developed? The purpose of this study was to investigate the impact that training in social emotional learning has on the pedagogy and practice of classroom teachers. It examined the effect the Canadian developed social emotional learning program Roots of Empathy (ROE) has on teachers, children, the classroom environment and, ultimately, on the broader community. This study documented how the social emotional learning (SEL) program influenced teachers and children who participated in it. It sought to understand how both the instructor training and program implementation impacted on the participants, what this meant for their understanding of SEL, how the children have responded to the program and how their behaviours and learning were changed by it. It investigated the participants' perceptions of the effectiveness of ROE as an SEL learning program, and its benefits and limitations.
\end{abstract}

The Roots of Empathy program was highly effective in developing emotional literacy. It made a positive contribution to the professional learning of the teachers and increased their awareness of the emotional competencies of the children they teach. It was evident that pro-social behaviour of the children in the Roots of Empathy classes increased while bullying and aggression decreased. 


\section{Introduction}

The message from the National Scientific Council on the Developing Child (2006) is clear: 'If we really want to build a strong platform for healthy development and effective learning in the early childhood years ... then we must pay as much attention to children's emotional wellbeing and social capacities as we do to their cognitive abilities and academic skills'. This is reinforced by the report to UNESCO, Learning: The Treasure Within, that says that schooling must have four key structures: 'learning to be, learning to do, learning to live together and learning to know' (Delors, cited in Forster, 2001: 1). The purpose of schooling then, goes far beyond the acquisition of academic skills and knowledge, to that of the moral, social and ethical development that underpins success in life.

There is an increasing emphasis on the need for teachers to embrace strategies that support the growth and development of social outcomes for children while helping them deal with the increasing challenges of today's classrooms. This is emphasised in the literature: 'we must stop looking for quick fixes and begin seeing what defines quality learning and teaching' (Fullan, cited in Zins et al., 2004: 36) and teachers 'must reconnect the nation's teachers with feelings of empowerment and spiritual joy that originally brought them to teaching and learning' (McCombs, cited in Zins et al., 2004: 36). This can be achieved by embracing social emotional learning (SEL) concepts and programs that balance reform agendas and recognise the goals of education as producing 'academically competent, responsible, productive, and caring students and citizens' (McCombs, cited in Zins et al., 2004: 37).

\section{Background}

The Western Australian Government has legislated that Curriculum Framework (Curriculum Council, 1998) learning outcomes, including 'core shared values' as social outcomes, must be the foundation of all learning and teaching programs for children in that state. Thus schools have undertaken to deliver curricula that support these values. In 2004, the Department of Education and Training (DET) instigated a trial of the Canadian based program Roots of Empathy (ROE) as a tool for developing these social outcomes by specifically teaching emotional literacy to guide children's behaviour and subsequently improve their academic performance. Seventeen schools committed to full participation in this trial.

This program was originally developed in response to the poor academic results of children living in the inner city areas of Toronto. Program instruction addresses all manner of social issues: bullying, smoking, child abuse and foetal alcohol spectrum disorder with the emphasis always on inculcating respect for oneself, understanding and compassion for others, and a sense of responsibility for the world, its citizens and future' (Gordon, 2005: 26). Gordon also established literacy learning centres for parents of children up to four years of age. In these centres, the focus was on parents interacting with their children through art, music and literature and providing the children with the space to play. She contended that a child's learning capacity was directly related to the amount of affection they 
received from their parents or care givers. Gordon was committed to integrating parenting centres into schools and from this the ROE program evolved.

As a result of active involvement in the WA trial during 2005 and 2006 as a trained ROE instructor, the researcher sought the views of other instructors and teachers who were participating in the trial to determine how this program had affected them, their classroom instructional programs and the children in their classes. Qualitative research methodology was implemented to elicit the perceptions of these participants. A phenomenological study was conducted to gain insight into how the participants viewed the ROE program as a method for developing SEL.

This research study was thus guided by the questions:

- What effect does training in social emotional learning, using the Roots of Empathy program have on teachers and their classroom practice?

- What changes occur in the classroom learning environment when teachers participate in program?

Data were collected using an introductory questionnaire followed by an interview. This enabled the researcher to identify, analyse and describe the commonalities of the perceptions of the participants and the 'essence-essential characteristic(s) —of the experience' (Fraenkel \& Wallen, 2003: 437).

\section{Overview of emotional literacy}

There is a growing body of research that reinforces what many teachers have believed for years: that success in school and life depends not only on academic ability, but also on the social emotional competency of the individual. Schools can be reassured by scientific and pragmatic evidence that time spent implementing SEL will enhance the academic success of students (McCombs, 2004). This is good news for schools that are deeply immersed in the pressure of standardised tests and academic accountability mechanisms. 'At a time when so many students at so many ages are flooded with anxiety as they struggle to succeed on standardized tests ... SEL programs [are] more relevant and useful to schools than ever before' (Goleman, 2004: vii).

\section{Social emotional learning-emotional intelligence-emotional literacy}

Throughout the literature there are numerous terms for social emotional learning. Daniel Goleman (1996) used the term 'emotional intelligence'. He acknowledged the origins of the term in the work of Salovey and Mayer (1990) whose view of SEL was that emotional intelligence related to social intelligence (Bar-On, 2005). Howard Gardner (1983, cited in Salovey \& Mayer, 1990) also noted this aspect of effective developmental growth in his theory of 'multiple intelligences'. All of these terms relate to the notion of 'a set of conceptually related mental processes involving emotional information' (Salovey \& Mayer, 1990: 189). In simple terms, emotional learning is the process 'through which we learn to recognise and manage 
emotions, care about others, make good decisions, behave ethically and responsibly, develop positive relationships and avoid negative problems' (Zins et al., 2004: 6). This learning is evident when one displays self-confidence, is motivated, is aware of what is expected, behaves appropriately, waits one's turn, follows instructions, actively listens and shows empathy. These relate to the social skills of cooperation, negotiation, handling emotions, teamwork and getting along with others (McCombs, 2004). Five key principles were seen as features of emotional intelligence. These are '(i) being aware of one's emotions, (ii) being able to manage one's own emotions, (iii) being sensitive to the emotions of others, (iv) being able to respond to and negotiate with other people emotionally, (v) being able to use one's own emotions to motivate oneself' (Salovey \& Mayer, 1990: 313). Based on these principles, a conceptual framework is presented that relates these mental processes to three components of expression and appraisal, regulation and adaptation.

\section{Emotional intelligence-how important is it?}

Many theories are supported by data that support the paradigm of an integrated 'broad interdisciplinary model of the developing child ... integrating affective, behavioural, cognitive, and linguistic development' (Chi-Ming et al., 2004: 66). Brain-based research is adding to the discussion on, and support for, the focus on emotional intelligence. Anatomical research is providing information on the ways that the brain processes functions related to social emotional learning and academic competencies (Bar-On, 2005). Success in life is thus determined by factors that relate to both cognitive intelligence (IQ) and emotional intelligence (EQ). It is significant that cognitive development is preceded by emotional development ( $\mathrm{Wu}$, 2000). It is also believed that emotional intelligence is not determined by genetics, but can be strengthened and nurtured by programs that teach emotional literacy.

Neuroscience also supports theories grounded on the importance of understanding social emotional learning, particularly in the context of 'how children's experiences and relationships affect the children's brain organisation, structuralization and development' (Chi-Ming et al., 2004: 74). It is recognised that educators must refocus on the curriculum for social emotional learning as evidence of its link with success in schools grows. 'Education must include all the elements needed for success in school and must refocus to prepare children for the tests of life, not for a life of tests' (Elias et al., 2003: 304). Neurological evidence also indicates that 'the emotional centers of the brain are intricately interwoven with the neocortical areas involved in cognitive learning' (Goleman, 2004: vii). A child who is distressed has a limited capacity to hear, understand or engage in learning, so for optimal learning the child's brain must be attuned to the environment, attentive, focused, motivated and engaged, and educators need to focus on a comprehensive, long-term approach that builds success for children across the domains of cognitive, affective and emotional learning through an integrated curriculum approach.

\section{How can emotional intelligence be developed?}

Developing emotional intelligence is about teaching skills that make the learner confident, motivated, aware of expected behaviour, able to manage personal impulses, seek help when appropriate, wait their turn, be aware and effectively 
interact with others. Goleman (1995, cited in $\mathrm{Wu}, 2000$ : 116) stated that emotional intelligence 'represents self-awareness and impulse control, persistence, zeal and self-motivation, empathy and social deftness'. Goleman further advocated a school curriculum that focuses on teaching these skills and helping students to manage their feelings and control their impulses, thus enabling them to resolve daily conflicts in socially acceptable ways. This premise was supported by Salovey and Mayer (1990) for two important reasons. Firstly it is recognised clinically that there is a difference in the capacity of people to understand and express their emotions and, secondly, the important underlying skills for competency in social emotional learning contribute to the mental health of the individual and can be taught.

\section{What are these social - emotional competencies?}

CASEL (Collaboration for Academic, Social and Emotional Learning, 2003, cited in Zins et al., 2004: 9) have developed a framework for the key competencies that researchers believe form the basis of effective practices in social emotional learning. These are summarised below.

\section{Self-awareness}

- identifying and recognising emotions

- accurate self-perception

- recognising strengths, needs, and values

- $\quad$ self-efficacy

- $\quad$ spirituality

\section{Social awareness}

- perspective taking

- empathy

- appreciating diversity

- respect of others

\section{Responsible decision making}

- problem identification and situation analysis

- problem solving

- evaluation and reflection

- personal, moral, and ethical responsibility

\section{Self-management}

- impulse control and stress management 
- self-motivation and discipline

- goal setting and organisational skills

\section{Relationship management}

- communication, social engagement, and building relationships

- working co-operatively

- negotiation, refusal, and conflict management

- help seeking and providing.

These skills must be developed in an environment that is conducive to learning, is caring, safe and supportive. 'Communication styles, high performance expectations, classroom structures, and rules, school organizational climate, commitment to the academic success of all students, district policies, and openness to parental community involvement are all important' (Zins et al., 2004: 8). From this CASEL model, opportunities evolve for rewarding positive behaviour and developing and recognising SEL competencies. As a consequence there is increased engagement in learning, with greater attachment and commitment to schooling resulting in improved academic performance and life success (cited in Zins et al., 2004: 9).

\section{What does this mean for schools?}

The recent report from the Australian Principals' Association Professional Development Council on the Mind Matters Project adds to the research on the importance of the classroom teacher in creating an environment that not only supports learning, but also improves students' well being. It raises the vital issue of supporting students with mental health difficulties. 'While it is not the job of a teacher to diagnose mental or physical health problems, with experience they can develop an awareness of potential issues and a range of strategies to deal with them within the parameters of their environment conditions ... Adults in schools are often the first point of contact for distressed students and parents' (Zilm, 2006: 10)

Schools need to understand that allowing time to enhance students' social emotional competencies is crucial. Current research shows that SEL programs contribute to the academic success of students as well as to their health and well being (McCombs, 2004). This means schools must create an environment in which these skills are taught, modelled and practised inside and outside the classroom. Educators need to be proactive in providing learning programs that will 'foster student motivation to stay in schools and work hard at learning goals, attention must be paid to the development of quality social and emotional programs that enhance student ability to integrate their cognitions, emotions and behaviour ... that foster ... autonomy, belonging, and competence' (Christenson \& Havsy, 2004: 71).

SEL programs are important for all levels of schooling. Early intervention for pre-school children who demonstrate unacceptable behaviours, reinforces the 
premise that it is more effective to work with the child at an early age rather than later in their school life (Morrison et al., 1999). This emphasises the need for schools to work closely with parents as early as possible to identify and support children who show disruptive behaviours. Other studies that focus on students with special needs have shown that intervention using the PATHS program has 'produced a sustained reduction in depressive symptoms reported by the children' (Chi-Ming et al., 2004: 66).

Research in secondary schools also supports the adoption of social emotional learning programs that have reduced the dropout and non-attendance rate of students (Zins et al., 2004). Studies of adolescent health and resilience also add to research showing that 'consistent evidence that perceived caring and connectedness to others is important for understanding the health of young people' (Bernard \& Marshall, 2001: 2). The report on the Mind Matters Project confirmed the value of 'creating classroom environments where all students feel safe, and feel a sense of connectedness to each other, the content, their learning and the teacher. Respectful, open and informed discussion about mental health issues in such an environment can support affected students by, in effect normalising the issues' (Zilm, cited in Griffiths, 2006: 10). This study found that the crucial factor when supporting the students was the teachers' belief in the relationship between positive mental health and good learning outcomes for students and that schools have a responsibility to provide care to students with high mental health support needs. This further emphasises the importance of training teachers to effectively implement SEL.

\section{Teacher training in SEL programs}

Training in emotional literacy is being increasingly recognised as schools consider the value of implementing an SEL program. Reports from research projects that have included teacher training in SEL clearly indicate that increased staff knowledge and skills, in what was termed 'mental health literacy', lead to a common language in this area. Changes in staff attitudes towards managing students, bullying and other challenges also followed from the professional development training of these teachers. Pre-service programs 'to equip graduates with knowledge and skills that will help them create supportive learning environments, which promote social and emotional well being as well as academic success' (Stafford, 2006: 2) are a government focus. The needs of pre-service teachers are further highlighted in the report by Winn (2006: 8) that emphasises that 'one of the biggest stressors facing pre-service teachers is how to cater for diversity in the classroom, and the impact this may have on an individual's emotional and social well being'. It is advocated that universities review the way they deliver their curriculum to better equip the teachers in catering for the needs of all children, especially those of diverse abilities and teacher training courses must develop these skills.

It is further argued that two key components need to be recognised by preservice teachers:

1. Young people's social and emotional well being has an impact on their learning, behaviour and success at school and teachers and schools can 
create environments that promote the social and emotional well being of young people.

2. Teachers have a duty of care toward any young person who is at risk of harm as a result of social or emotional difficulties; this requires the capacity to recognise troubled young people and refer them to appropriate support agencies (Hazel \& Vincent 2006: 7).

\section{What are the characteristics of effective SEL programs?}

CASEL also presents essential characteristics of effective SEL programs. These are summarised in Table 1 and can be a useful tool for analysing and evaluating any SEL program under consideration.

Table 1. Essential characteristics of effective SEL programming (Collaboration for Academic, Social and Emotional Learning, 2003, cited in Zins et al., 2004: 10-1).

\begin{tabular}{|c|c|}
\hline $\begin{array}{l}\text { Addresses affective and } \\
\text { social dimensions of } \\
\text { learning }\end{array}$ & $\begin{array}{l}\text { - builds attachment to school through caring, } \\
\text { engaging, interactive, co-operative classroom, } \\
\text { and school-wide practices } \\
\text { - strengthens relationships between students, } \\
\text { teachers, other school personnel, families, and } \\
\text { community members } \\
\text { - encourages and provides opportunities for } \\
\text { participation } \\
\text { - uses diverse, engaging teaching methods that } \\
\text { motivate and involve students } \\
\text { - promotes responsibility, cooperation, and } \\
\text { commitment to learning } \\
\text { - nurtures sense of security, safety, support and } \\
\text { belonging } \\
\text { - emphasises cultural sensitivity and respect for } \\
\text { diversity }\end{array}$ \\
\hline
\end{tabular}




\begin{tabular}{|c|c|}
\hline $\begin{array}{l}\text { Leads to coordinated, } \\
\text { integrated and unified } \\
\text { programming linked to } \\
\text { academic outcomes }\end{array}$ & $\begin{array}{l}\text { - offers unifying framework to promote and } \\
\text { integrate social-emotional and academic } \\
\text { development } \\
\text { - integral aspects of formal and informal academic } \\
\text { curriculum and daily routines (e.g., lunch, } \\
\text { transitions, playground) } \\
\text { - provided systemically to students over multiple } \\
\text { years, pre kindergarten through high school. } \\
\text { - coordinated with student support services efforts, } \\
\text { including health, nutrition, service learning, } \\
\text { physical education, psychology, counselling, and } \\
\text { nursing }\end{array}$ \\
\hline $\begin{array}{l}\text { Addresses key } \\
\text { implementation factors } \\
\text { to support effective } \\
\text { social and emotional } \\
\text { learning and } \\
\text { development }\end{array}$ & $\begin{array}{l}\text { - promotes a safe, caring, nurturing, cooperative, } \\
\text { and challenging learning environment } \\
\text { - monitors characteristics of the intervention, } \\
\text { training and technical support, and environment } \\
\text { factors on an ongoing basis to ensure high - } \\
\text { quality implementation } \\
\text { - provides leadership, opportunities for } \\
\text { participation in planning, and adequate resources } \\
\text { - institutional policies align with and reflect SEL } \\
\text { goals } \\
\text { - offers well planned professional development, } \\
\text { supervision, coaching, support, and constructive } \\
\text { feedback }\end{array}$ \\
\hline $\begin{array}{l}\text { Involves family and } \\
\text { community partnerships }\end{array}$ & $\begin{array}{l}\text { - encourages and coordinates efforts and } \\
\text { involvement of students, peers, parents, and } \\
\text { educators, and community members } \\
\text { - SEL-related skills and attitudes modelled and } \\
\text { applied at school, home, and in the community }\end{array}$ \\
\hline
\end{tabular}




\begin{tabular}{|l|l|}
\hline $\begin{array}{l}\text { Design includes } \\
\text { continuous } \\
\text { improvement, outcome } \\
\text { evaluation and } \\
\text { dissemination } \\
\text { components }\end{array}$ & $\begin{array}{l}\text { uses program evaluation results for continuous } \\
\text { improvement to determine progress toward } \\
\text { identified goals and needed changes }\end{array}$ \\
& $\begin{array}{l}\text { multifaceted evaluation undertaken to examine } \\
\text { implementation, process, and outcome criteria }\end{array}$ \\
& results shared with key stakeholders \\
\hline
\end{tabular}

\section{Implementation of Roots of Empathy}

The ROE program uses this research as the basis for the program curriculum, building on and extending this 'dynamic emotional exchange' (Zahn-Waxler, date: 21) between the visiting mother and baby as the springboard for learning empathy that involves all participants, children, teachers, parents and community.

Throughout the year, a neighbourhood baby, the ROE baby and parent(s) visit a classroom nine times. These visits are facilitated by a certified ROE instructor who works with the class before, during and after each visit to coach the students to observe a 'baby's development, celebrate milestones, interact with the baby and learn about the infant's needs and temperament. Children learn messages of social inclusion ... to respect and build consensus ... how to contribute to a safe and caring classroom ... about emotional literacy' (Gordon, 2005: 6). Fathers are encouraged to attend the family visits as their presence often provides a much needed source of male nurturing and contact that is missing from the lives of many children today.

Learning originates from the baby visits, with themes developed throughout the year in a curriculum that is designed across the years $\mathrm{K}-8$. These themes cover the topics of crying, caring and planning, emotions (including bullying), sleep and communication. Connections are made with the learning areas of literacy, writing, art, music, mathematics and science. Discussion of child abuse, foetal alcohol spectrum disorder and violence is facilitated by the instructor with the classroom teacher's support.

Pre-visit and post-visit lessons build on the experience of the family visits and connect with the themes of the program. A baby doll is used for the other lessons to engage the children and connect with the family visits. This doll is frequently used to demonstrate aspects of the curriculum such as baby safety and ways of soothing a baby. The children handle the doll as they would a human baby. These lessons may begin with the sharing of literature that develops the theme and links to the children's emotions and experiences. The activity that follows encourages the children to express their own emotions. For example in the theme of 'Crying' the children draw and write about a time when they have cried. This artwork is often compiled into a class booklet that is a stimulus for further follow-up activities, discussion by the class teacher and free-reading experiences. 
The lesson plan format is clearly documented in the ROE Curriculum Manual and covers all aspects of the lesson: aims, preparation, materials, introduction, activities and conclusion. These lessons are sequenced and divided into year level groups across the school, with lessons for preschool and kindergarten; grades 1-3, 4-6 and 7-8. Planning and reflection tools are included and instructors are encouraged to use the formats provided. Feedback forms are completed at the end of the program by the children, teachers and instructors and returned to ROE in Canada for analysis and ongoing evaluation of the program.

Teachers are trained on two levels: firstly as instructors of Roots of Empathy, which incorporates extensive theory that supports emotional literacy and program implementation; and secondly, as classroom teachers who will be responsible for classroom implementation. This training includes an overview of the objectives of ROE and how it operates in the classroom.

Research on the implementation components of ROE shows that in reviewing the steps that $\mathrm{ROE}$ has taken to promote sound and rigorous implementation, it is clear that they have included every one of the components espoused by Weissberg and Greenberg. Hence ROE has the highest degree of implementation promotion' (Schonert-Reichl, 2005: 244). This demonstrates a high commitment to the program delivery in its full integrity.

\section{Methodology}

The research design for this study used the qualitative research methodology of phenomenology to investigate the reactions and perceptions of those involved in the phenomenon by questioning and interviewing all participants. The researcher sought insights into participants' reactions to the Roots of Empathy program and built a descriptive narrative of how this SEL program had affected the teachers and their classroom practices.

'Phenomenologists generally assume that there is some commonality to the perceptions that human beings have in how they interpret similar experiences, and they seek to identify, understand, and describe these commonalities' (Fraenkel \& Wallen, 2003: 437). By incorporating this research methodology, the researcher found that there were common essential characteristics of this experience in implementing ROE. These served to generate themes for discussion of the ROE experience and were supported by the SEL literature. Conclusions and recommendations emerged from the participants' perceptions, with suggestions for further research also arising from this phenomenon.

Purposive samplings of participants were used as it was essential that the teacher participants had been trained in ROE, or were involved in the school implementation of the program. An initial questionnaire was sent to all participants in the 15 trial programs in Western Australian schools. From the data returned, a follow-up interview was conducted with eight willing participants from seven different school settings. Four of these participants were teachers who were experiencing the ROE program for the first time, delivered in their classroom by a 
ROE instructor. The other four participants were teachers who had trained as ROE instructors and were presenting the program in another teacher's classroom.

Participants delivered the program in schools from a variety of socioeconomic locations - urban and rural settings of varying populations. This pilot project targeted only children in Years One or Two. The researcher visited each participant in the classroom to build a comprehensive picture of the conditions in which the program was being delivered.

The initial questionnaires used for data collection gave a comprehensive view of the perceptions of the participants, noting their background, knowledge of SEL, experience in teaching emotional literacy, their opinion of the ROE program as a tool for developing SEL, their feelings about SEL and ROE and what they perceived as happening when the ROE program was delivered. These were subsequently followed by interviews of eight respondents. Themes emerged from the analysis of these questionnaires and interview transcriptions. These are presented as the key findings of this study.

\section{Results}

\section{Teacher knowledge and pedagogy}

ROE was regarded by all participants as a highly effective tool for teaching social emotional learning, frequently propounded by all participants in this study as 'I feel so connected to it because I see how effective it is ... I feel very strong about teaching it because it's such a tool to have ... such a terrific thing to have as a child ... if they can tell each other or adult respectfully how they feel about something it makes such a difference'. All participants were committed to the importance of SEL in their teaching and learning. They considered SEL essential to the academic learning that underpinned the teaching philosophy of all participants. The pedagogical understandings in the ROE program were consistent with each participant's philosophy of learning and teaching. They clearly saw the purpose of SEL and were confident, articulate and passionate when saying how the ROE program had helped them teach emotional literacy. All participants had a clear sense of purpose and a very strong commitment to program delivery. This was demonstrated by comments such as ROE 'continues to develop as my own emotional intelligence grows ... I am increasingly aware that many of us need direct and explicit teaching/learning in order to relate to others'.

The consistency of responses and the sound knowledge of the participants highlighted the effectiveness of the training program and ROE curriculum materials as an SEL program. Participants who had had previous training in SEL, or were confident in their knowledge, felt that ROE had nevertheless improved their knowledge and understanding. This supports the findings that 'many new professionals entering the teaching force need training in how to address social emotional learning to manage their classrooms more effectively, to teach their students better, and to cope successfully with students who are challenging' (Zins et al., 2004: 4). 
The results of this study clearly demonstrate that teachers need training in SEL and that ROE meets this need. "[T]eacher candidates receive little to no instruction in social and emotional development or exposure to SEL programs until they are required to teach them in the schools' (Fleming \& Bay, cited in Zins et al., 2004: 108). Fleming and Bay emphasised the impact that the training in SEL has had on teachers, who became confident, committed and passionate about how ROE had helped them teach SEL more effectively. The teachers also claimed that ROE had changed their relationships with children and revitalised their classroom teaching. This significantly endorses Ingersoll (cited in Zins et al., 2004: 108) who said that 'training in SEL has the potential to reduce teacher attrition by affecting factors associated with retention, such as reducing job-related stress, increasing feelings of effectiveness and job satisfaction, reducing student-teacher conflicts and discipline problems and improving classroom management skill'.

It is essential that teachers are competent in their knowledge and understanding, and deliver effective strategies for teaching SEL, as 'the recognised need for SEL is greater than at any time in recent decades, thereby presenting an opportunity to which educators and policy makers must give serious consideration' (cited in Zins et al., 2004: 5). Educators therefore must refocus on the place of social emotional learning as there is growing evidence of the link between SEL and school success. Elias et al. (2003: 304) asserted that 'education must include all the elements needed for success in school and must refocus to prepare children for the tests of life, not for a life of tests'. ROE is unique in the experiential learning that occurs and it is widely recognised as being 'nothing short of revolutionary in its potential to change the way young people see themselves and their world' (Gordon, 2005: 26).

\section{Changes in teacher behaviour}

Teachers shared the ways that their personal relationships and behaviours had been changed by the ROE program, where the role of the teacher is essential for establishing an effective classroom climate for learning. 'Arguably, teachers are the critical element in creating learning environments in which children's understanding and skills ... are advanced' (Fleming \& Bay, cited in Zins et al., 2004: 95). All participants were excited and enthusiastic about the effect of ROE on their ability to see another side of children, being more aware of the emotions of everyone around them and having greater empathy for children, colleagues and parents. They listened more attentively, better appreciated the capacity of children to empathise and were amazed at the perception of the children in their classes of the emotions of the baby and subsequently their peers. These changes were consistent with 'such skills [SEL] ... will help ... teachers to manage their own stress more effectively and to engage in problem solving more skilfully in their own lives' (Zins et al., 2004: 4).

Similarly, Gordon (2005: 196) contended that 'teachers find that their own empathy for their students deepens. This is often reciprocated as students become aware of the teachers' moments of frustration and offer help'. The importance of the relationship between the teacher and his or her students cannot be underestimated. In response to the question 'What makes children decide to learn?' Gordon (2005: 201) 
wrote that 'one of the most significant factors is the teacher's relationship with the child. Children learn most from human interaction and, within that, learn most from people who have positive regard for them'.

In this study, ROE was acclaimed as having a positive effect on many relationships within the school community. Examples were cited of parents commenting positively about teachers and how they appeared to be more sensitive and empathetic. Instructors noted a 'richer partnership' with teachers as they delivered the program, while parents felt appreciated and privileged for having been part of the ROE program. ROE was acclaimed by all participants as having a significant influence on their interactions with children. This is a significant result as 'caring relations between teachers and students foster a desire to learn and a connection to school' (Walberg et al., 2004: 210). The determination of all participants to make ROE effective for them as a SEL program is acknowledged by the researcher. Even when a situation was quite challenging for some participants, they persevered to successfully implement the program because of their belief in ROE as beneficial to the social emotional learning of the children and their academic outcomes.

\section{Impact on the children}

The ROE program affected the children participating in the program in three key areas: behaviour; language acquisition of emotional literacy; and understanding of child development.

\section{Children's behaviour}

One teacher clearly articulated the impact of ROE on children's behaviour, stating that there is 'a more sensitive, gentle, environment. Children are more aware of the needs of their peers ... more willing to help one another and wanting to know the reason why that person is sad or how their feelings are hurt'. She concluded that there is 'a greater understanding of each other and their feelings', a statement echoed by all participants in the study. Teachers also emphasised how the children were more sensitive and caring of each other. They insisted that their students were now more aware of the needs of their peers and that there were observable changes in the gentleness they showed to each other, the ROE baby and the doll used in the lessons and during experiences.

Teachers also agreed that bullying had been reduced, sharing stories of how they used the program to modify the behaviour of some children. One instructor, in her role as deputy principal, was often in the playground and observed that there is 'definitely a decrease in bullying. They definitely have a better understanding of showing more care and concern ... we are changing attitudes'. This change is consistent with the research findings of Schonert-Reichl (2005: 247) that the 'ROE program children, relative to comparison children, exhibited significant increases in emotional understanding and pro-social behaviours and significant decreases in aggressive behaviours'. 
Results from this study emphasise the importance of SEL while neuroscience research offers another dimension, that 'the emotional centers of the brain are intricately interwoven with the neocortical areas involved in cognitive learning' (Goleman, 2004: vii). A child who is distressed has a limited capacity to hear, understand or engage in learning. It is essential that children are explicitly taught emotional literacy to enable them to perform to their full potential.

\section{Children's language of emotional literacy}

The language benefits, according to one instructor, accrue to students who have speech and language impairments. She said 'I can't speak highly enough of what they have gained in empathy in the literacy of language. They didn't have the language - happy, sad or angry ... then by the end of the year ... they were able to use a huge range of literate language'. Participation in ROE had significant effects on the behaviour of children, with decreased anxiety, increased self-confidence, greater empathy toward each other and respect for the doll in the dramatic play centre. As described by this instructor, 'It was just huge. It's amazing, very exciting'. Other study participants were similarly impressed by the program's results. Children were frequently observed using a wider range of emotional language and sharing their feelings with others. They demonstrated a greater awareness of their own emotions and felt safe when sharing these with others, particularly in the opportunities that arose during the ROE lessons.

\section{Children's knowledge of child development}

Children learnt a great deal about child development through the interaction, observation and discussion during the family visits. All participants supported the view of one teacher that the children 'especially love the family visits, and were always keen to contribute their views and ask questions of the mother. They were able to observe changes in the baby and were always respectful of the baby and the mother'. She also reported that the children were fascinated with the baby and took an active interest in the information presented by the ROE curriculum. They were keen to learn developmental terms and especially to discuss the safety aspects of a baby's development. Another teacher commented 'I have been amazed at the depth of perception that has come from my 6 year olds ... [I have a greater] awareness that children are so much more capable of the emotional side of life and what it means'.

The findings from this study clearly demonstrate that ROE has significantly influenced children who participated in the program and positively affected their behaviour and knowledge of emotional language, and increased their knowledge of child development.

\section{Program implementation-what makes it work?}

This research study also identified a number of factors that supported the effective implementation of the ROE program. These are consistent with the findings of Weissberg and Greenberg (1998, cited in Schonert-Reichl, 2005) who reported a 
strong correlation between the characteristics of effective implementation and the ROE program.

\section{Program structure}

The ROE curriculum is carefully and clearly organised into a structure that explicitly addresses the purpose, goals, aims, lesson content, resources and learning strategies of each lesson. Lessons are documented in the Curriculum Manual, with material addressing the various grade levels of the K-8 program. A Training Manual gives information to support the program delivery.

\section{Curriculum content}

The content of the curriculum is what makes this program so powerful. As one of the participants said: 'You all go through a journey together and while there is a curriculum I always feel like the curriculum is second to what is actually happening because what happens in the baby visit is about what the baby does ... it's just an experiential thing for everyone involved ... it reinforces the principles of teaching and learning that we know'. In her summary of the program she stated 'It's a very peaceful sort of program ... its like that little pocket of time when everyone sits back and watches a baby grow'.

These comments were reinforced by all participants who described the content of the program as 'the building blocks'. Another participant described ROE as all encompassing. She used the terms 'relevant, inclusive, collaborative, community development ... Curriculum Framework principles on every front. Babies are non-threatening, interesting, alive and fascinating for children. What better way can there be to help children to grow in emotional literacy?'

The content of ROE is 'a rich, vital, and highly rewarding classroom parenting program that teaches human development, emotional literacy and nurtures the growth of empathy' (Gordon, 2005: 1). The findings of this study strongly endorse this curriculum as being highly engaging and effective in meeting these objectives. The message from one participant was strong, clear and passionate in her overview of ROE stating '[It's about] touching emotional literacy ... getting to the depth of their being ... deep down it touches them and they relate back to the baby'. She further described it as a 'wonderful program with the quality of internal messages that the people get ... just like the effect it has on our kids ... they just love it'

\section{ROE training and mentoring}

The training structure for the implementation of the ROE program is extremely detailed and rigorous and specifies the roles of all those concerned with its operation. A mentoring program is integrated into the training and ongoing professional development program plan. This structure is the key to successful implementation and outcomes of the program. 


\section{Analysis and evaluation}

Integral to the implementation of ROE is review and feedback. This enables the Board of the Roots of Empathy program to make informed decisions about its outcomes while supporting continuous improvement. It contributes to the evidenced based research of the longitudinal effects of the program, documented by CASEL as a key criterion in an effective SEL program (cited in Zins et al., 2004: 11). Research by external agencies has also contributed to the development of the program (Schonert-Reichl, 2005).

\section{Choice of participants}

All participants in this research study were given the choice to participate in the ROE program. This was considered essential because the program demanded collaboration, timetabling and commitment by all parties for successful implementation.

The role of the classroom teacher was also considered crucial to successful implementation of ROE. Essentially, the teacher must understand the program structure and the need for SEL, be willing to commit the time to fulfil the program components and work collaboratively with the instructor and family for effective implementation.

Because the structure of the ROE program demanded the collaboration of the whole school community, it was essential that all involved supported the program, i.e., the school principal, the classroom teacher, the ROE instructor, the ROE family, children and parents. The findings from this study showed that a sense of community was generated by the nature of the program, with one participant describing it 'as a ripple that's going on'. Again this is viewed as an essential characteristic by CASEL, reinforcing the partnerships with family and community (cited in Zins et al., 2004: 11).

\section{Department of Education (DET) support}

The support of the Department of Education and Training (DET) was crucial to the implementation and sustainability of the ROE program in Western Australia. Because of the financial support of DET's Behaviour Standards and Wellbeing Directorate and its coordination of training, the program was successfully implemented. It is essential, however, that there is a strong policy and resourcing commitment to effectively sustain ROE. There is an increasing demand for ROE to be made available to other schools and a long-term action plan is essential to secure the future of ROE in Western Australia.

\section{Conclusion}

The SEL ROE program significantly improved the attitudes, knowledge and social emotional competencies of all participating teachers and children. A decrease in the frequency of bullying and an increase in pro-social behaviours were reported by all 
participants. Partnerships between teachers, children, parents and the school community strengthened.

All educators who work with children need specialised training in SEL that will subsequently enable them to develop these skills in all children. This training should incorporate the 'science of early childhood and early brain development ... to a broad range of policies ... including child care, adult mental health, child welfare and public assistance, among others' (National Scientific Council on the Developing Child, 2006).

All participants rated ROE as highly effective at teaching emotional literacy. The program had positive effects on children's pro-social behaviours, development of teachers' and children's empathy, knowledge of emotional literacy as well as a sound understanding of child development. It promoted positive relationships within the school and community.

\section{Recommendations}

\section{Resources}

All schools need to be well resourced to effectively implement SEL programs such as Roots of Empathy. Schools need to recognise the value of the time invested in SEL programs as essential for the healthy development and learning of children. Teachers must have their knowledge and skills enriched so that they can develop the emotional literacy skills of their students and be alert to mental health problems that may be experience by those in their care.

\section{Sustainability}

Roots of Empathy needs to be sustained to ensure it is accessible to all educators interested in its extension and adoption. Currently only 15 instructors are certified to deliver this curriculum in Western Australian. In 2007 only four instructors were implementing the program due to lack of funds and DET commitment. Funding for the programs in operation was accessed through business sponsorship and local government support.

A long-term plan for the continued roll out of training and mentoring needs to be developed and resourced. Without strong leadership and advocacy within the education sector of Western Australia, the growth and sustainability of this program and indeed other SEL programs are at risk of failure.

\section{Whole school approach}

A whole school approach that is endorsed by the school principal is essential for effective long-term implementation of ROE. It is further recommended that all stakeholders be given the choice to participate in the SEL program and fully informed of their obligations and responsibilities and supported by strong leadership. 
Principals, teachers, parents and students must be well informed of the goals and commitment to the program and the implementation obligations. More instructors need to be trained to make ROE accessible to all interested communities and an affordable implementation plan negotiated with the Canadian Board of Roots of Empathy.

\section{Training model}

A model of professional development needs to be negotiated between the ROE Foundation of Canada and the Western Australian Government. This will then support local ROE mentors and instructors to advance to the role of ROE Trainers, ensuring long-term sustainability of the program in WA. This sustainability and development is currently hindered by the limited access that is available to interested parties due to the lack of certified personnel. It can only be achieved by negotiation between the ROE Foundation of Canada and the Western Australian Government.

\section{Longitudinal evaluation}

Ongoing evaluation is critical to future sustainability and implementation plans to accurately determine the longitudinal impact of ROE, or any other SEL program adopted by schools. It is also essential that this process is included in the ongoing resourcing to add validity to the program in an international context. It is further recommended that ongoing longitudinal evaluation is integral to any SEL program implementation.

\section{Pre-service training}

Pre-service training in SEL must be included as an essential component of teacher training programs in universities with a major focus on practical, effective methods of classroom implementation. ROE needs to be accessible for pre-service teachers, given the evidence based research on its impact on the SEL of teachers, children and the learning environment. All teacher graduates need to be confident in teaching emotional literacy. Courses in pre-service education must develop the knowledge and skills of graduates to effectively implement SEL. ROE is powerful in achieving this understanding and needs to be promoted as an effective SEL program.

\section{Professional learning}

Based on research that supports the importance of SEL in the early years of a child's development, it is recommended that SEL programs, such as ROE, become mandatory units in the training of all educators who work in the care and education of children.

'Providers of early care and education must have sufficient knowledge and skills to help children who present with common behaviour problems early on ... greater attention must be focused on the social and emotional development of children ... and programs must have access to specialized mental-health services that have professionals available to meet the needs of young children whose 
problems cannot be addressed adequately by front-line staff' (National Scientific Council on the Developing Child, 2006).

\section{Considerations for future research}

Future research needs to establish the longitudinal benefits of programs that address SEL, such as ROE, not only for the social emotional well being, but also for ongoing academic achievement of the children that participate in the program. A study comparing the academic performance of children receiving SEL training with those under regular classroom instruction would be valuable in further building the research base for SEL.

\section{References}

Bar-On R, 2005, 'The Bar-On model of emotional-social intelligence (ESI)'. Psicothema, 17, 1-28.

Benard B \& Marshall K, 2001, Protective factors in individuals, families, and schools: National longitudinal study on adolescent health findings. National Resilience Resource Center, University of Minnesota, Minneapolis.

Chi-Ming K, Greenberg MT \& Kusche CA, 2004, 'Sustained effects of the PATHS curriculum on the social and psychological adjustment of special education'. Journal of Emotional and Behavioural Disorders, 12(2), 66-78.

Christenson SL \& Havsy LH, 2004, 'Family-school-peer relationships: significance for social, emotional, and academic learning'. In Zins J, Bloodworth R, Weissberg RP \& Walberg HJ (eds), Building academic success on social and emotional learning. Teachers College Press, New York, 59-75.

Conduct Problems Prevention Research Group, 1999, 'Initial impact of the fast track prevention trial for conduct problems: Classroom effects'. Journal of Consulting and Clinical Psychology, 67(5), 648-57.

Curriculum Council, 1998, Curriculum framework. Author, Osborne Park.WA

Elias MJ, Zins JE Graczyk PA \& Weissberg RP, 2003, 'Implementation, sustainability, and scaling up of social-emotional and academic innovations in public schools'. School Psychology Review, 32(3), 303-19.

Emerson L, 2007, Writing Guidelines for education students. Thomson, Melbourne.

Forster M, 2001, 'The social outcomes of schooling interpersonal, moral and ethical aspects'. Paper presented for the Education Department of Western Australia: Australian Council for Educational Research.

Fraenkel JR \& Wallen NE, 2003, How to design and evaluate research in education (5th ed.). McGraw-Hill, New York. 
Goleman D, 1996, Emotional intelligence: Why it can matter more than I.Q? Bloomsbury Press, London.

Goleman D, 2004, Building academic success on social and emotional learning. Teachers College Press, NY.

Gordon M, 2001, Roots of empathy training manual. Early Years, Ontario.

Gordon M, 2005a, Roots of empathy mentor's manual. Early Years, Ontario.

Gordon M, 2005b, Roots of empathy changing the world child by child. Thomas Publishers, Toronto.

Hazel G \& Vincent K, 2006, 'Finding a place in teacher education'. Education Connect, 3, 3-9.

Hazel G \& Kay-Lambkin F, 2006, 'Climbing the motivational ladder'. Education Connect, 3, 10-5.

Lopes PN \& Salovey P, 2004, 'Toward a broader education: Social, emotional, and practical skills'. In Zins JE, Bloodworth, MR, Weissberg RP \& Walberg HJ (eds), Building Academic Success in Social and Emotional Learning. Teachers College Press, New York, 76-93.

McCombs BL, 2004, 'The Learner-centered psychological principles: A framework for balancing academic achievement and social-emotional learning outcomes'. In Zins JE, Bloodworth, MR, Weissberg RP \& Walberg HJ (eds), Building Academic Success in Social and Emotional Learning. Teachers College Press, New York, 23-39.

Morrison M, Macdonald G \& LeBlanc T, 1999, 'Conduct problems in young children: Effective early intervention strategies'. Oacas Journal, 43(1), 22-7.

National Scientific Council on the Developing Child, 2006, 'Children's emotional development is built into the architecture of their brains'. <www.developingchild.net> viewed January 2007.

Sala F, 2005, 'Do programs designed to increase emotional intelligence at workwork?'<www.eiconsortium.org> viewed August 2005.

Salovey P \& Mayer JM, 1990, 'Emotional intelligence'. In Jenkins J, Oatley K \& Stein NL (eds), Human emotions a reader. Blackwell Publishers Ltd, Massachusetts, USA.

Schonert-Reichl KA, 2005, 'Effectiveness of "Roots of Empathy" program in promoting children's emotional and social competence: A summary of research outcome findings'. In Gordon M (ed.), Roots of Empathy Changing the World Child by Child. Thomas Allen Publishers, Toronto, 239-52. 
Shriver, T P, \& Weissberg, RP 2005, No emotion left behind, The New York Times August 2005, p.16.

Stafford, K 2006, 'Welcome’, Education Connect, vol. 6, pp. 2-15.

Telethon Institute of Child Health Research 2006, 'The evaluation of 'Roots of Empathy' in Western Australian Schools 2005', a report for the Education Department of Western Australia.

Treasure, $\mathrm{T}$ 2005, The importance of fostering children's social emotional development during the early childhood years and how this can be enhanced using the PATH'S program. Unpublished Honours Thesis, Curtin University of Education, WA.

Walberg, H J, Zins, JE \& Weissberg, RP 2004, 'Recommendations and conclusions: Implications for practice, training, research and policy', in eds JE Zins, MR Bloodworth, RP Weissberg \& HJ Walberg, Teachers College Press, New York, pp. 209-218.

Winn S, 2006, 'Diversity in the school environment: Catering for students who are deaf or hearing impaired in an inclusive setting'. Education Connect, 4, 8-9.

Wu YS, 2000, 'Guidelines for instructional sequencing in emotional literacy learning using PATHS curriculum as an example'. In National Convention of the Association for Educational Communications and Technology. Denver, $\mathrm{CO}$.

Zilm T, 2006, 'Teachers can and do make a difference'. Education Connect, 4, 101.

Zins JE, Bloodworth MR, Weissberg RP \& Walberg HJ, 2004, 'The scientific base linking social and emotional learning to school success'. Zins JE, Bloodworth MR, Weissberg RP \& Walberg HJ, Teachers College Press, New York, 3-22. 